\title{
RANCANG BANGUN SISTEM FALL DETECTION UNTUK ORANG LANJUT USIA BERBASIS INERTIAL MEASUREMENT UNIT
}

\author{
Muhammad Firmansyah ${ }^{1}$, Achmad Rizal $^{2}$, Erwin Susanto $^{3}$ \\ ${ }^{1,2,3}$ Prodi S1 Teknik Elektro, Fakultas Teknik Elektro, Universitas Telkom \\ ${ }^{1}$ muhammadfirmansyah@students.telkomunivesity.ac.id, \\ 2achmadrizal@telkomuniversity.ac.id, 3erwinelektro@telkomuniversity.ac.id
}

\begin{abstract}
Abstrak
Ketika manusia memasuki usia senja, maka kemampuan fisik dan daya konsentrasinya juga menurun. Dari hal itu, tentunya ada hal yang dikhawatirkan, yaitu hilangnya keseimbangan yang menyebabkan terjatuh. Apabila jatuh dalam dalam kondisi ramai hal ini tidak menjadi masalah yang besar, namun hal yang paling dikhawatirkan apabila jatuh dalam kondisi sepi. Tentunya akan menimbulkan dampak yang serius bagi orang lanjut usia tersebut. Dalam penelitian ini, dibuat sebuah alat pendeteksi jatuh untuk orang lanjut usia menggunakan microcontroller dan sensor inertial measurement unit (IMU). Microcontroller akan dihubungkan dengan sensor IMU dan modul GSM/GPS/GPRS dan dicatu menggunakan power bank sehingga dayanya dapat diisi ulang. GPS berfungsi untuk menentukan lokasi jauh sementara itu modul GSM berfungsi untuk mengirim data. Untuk mengklasifikasi jatuh, digunakan sebuah algoritma yang dibuat berdasar pada data percobaan. Informasi- informasi yang didapat dari sistem kemudian akan dikirim melalui pesan singkat yang akan terima oleh smartphone yang telah ditentukan, yang mencakup informasi indikasi jatuh dan koordinat lokasi jatuh. Hasil pengujian menunjukkan akursi mencapai $82 \%$ dari keseluruhan percobaan.
\end{abstract}

Kata Kunci: IMU, microcontroller, deteksi jatuh, smartphone

\section{Abstract}

When humans enter old age, the physical ability and power of concentration also decrease. From that, of course, there is something to worry about, namely the loss of balance that causes a fall. If it falls in a crowded condition, this is not a big problem, but it is most feared if it falls in a deserted situation. Surely it will have an important impact on the elderly. In this study, a fall detection device for the elderly using a microcontroller and an inertial measurement unit (IMU) sensor is made. The microcontroller was connected to the IMU sensors and GSM GPS/GPRS modules and will be supplied using the power bank so that the equipment can be recharged. GPS function to determine the location of the fall while the GSM module serves to send data. To classify the fall condition, be used an algorithm which was made by experimental data. The Information obtained from the system will be sent via short message, and that will be received by a smartphone which we were determined the previously, which includes information indicative of fall and the location coordinates of fall. The testing result showed that accuracy was $82 \%$ for entire experiments.

keywords: IMU, microcontroller, fall detection, smarthphone

\section{Pendahuluan}

Kemampuan fisik dari orang lanjut usia akan menurun seiring dengan proses penuaan, sehingga meningkatkan potensi terjadinya jatuh. Jatuh pada orang lanjut usia dapat memberikan dampak serius, seperti luka dan bahkan dapat meningkatkan resiko kematian. Saat ini tengah dikembangkan teknologi untuk mendeteksi jatuh dengen berbagai metode, baik menggunakan kamera, maupun menggunakan sensor- sensor yang dapat mendeteksi pergerakan.

Pada penelitian ini dibuat suatu alat yang dapat mendeteksi jatuh penggunanya, dengan memanfaatkan kemiringan sudut dan percepatan sudut dari sensor IMU (Iinertial measurment unit), selain itu alat ini dilengkapi dengan modul GPS/GPRS/GSM sehingga sistem yang dibuat dapat mengirimkan output berupa pesan singkat indikasi jatuh dan juga lokasi pengguna berada. alat dibuat dengan mempertimbangan titik berat tubuh manusia.

Yang menjadi nilai tambah adalah, catu daya pada alat ini menggunakan power bank sehingga memudahkan para penggunanya untuk memonitoring daya, yang diharapkan dapat mencegak alat mati ketika digunakan. Alat yang dibuat ini diharapkan membantu mengurangi hal yang tidak diinginkan dari keadaan jatuh. 


\section{Teori Penunjang}

\subsection{Arduino Uno}

Arduino uno adalah salah satu produk berlabel Arduino yang sebenarnya adalah salah satu papan elektronik yang mengandung mikrokontroler ATmega328. Peranti ini dapat dimanfaatkan untuk mewujudkan rangkaian elektronik dari yang sederhana hingga yang kompleks. Pengendalian LED hingga pengontrolan robot dapat diimplementasikan dengan menggunakan papan yang berukuran relatif kecil ini. Bahkan, dengan penambahan komponen tertentu, peranti ini bisa dipakai untuk pemantauan jarak jauh melalui internet, misalnya pemantauan kondisi pasien di rumah sakit dan pengendalian alat-alat di rumah [1].

\subsection{Shield GPS/GPRS/GSM TEL0051}

Shield ini merupakan Quard-Band GSM/GPRS yang bekerja pada frekuensi EGSM 900MHz/DCS $1800 \mathrm{MHz}$ and GSM850 MHz/PCS 1900MHz. Shield Ini juga mendukung teknologi GPS untuk navigasi satelit. Hal ini memungkinkan untuk robot anda atau sistem kontrol anda mengirim pesan menggunakan jaringan GSM. Shield ini dikontrol melalui perintah (GSM07.07,07.05 dan SIMCOM enhanced AT Commands)[2].

\subsection{Inertial Measurment Unit (IMU)}

Inertial Measurement Unit (IMU) merupakan alat yang memanfaatkan sistem pengukuran seperti gyroskop dan akselerometer untuk memperkirakan posisi relatif, kecepatan, dan akselerasi. IMU adalah bagian dari navigasi system yang dikenal sebagai Inertial Navigation System (INS). Pertama kali didemonstrasikan oleh S. Draper tahun 1949, IMU menjadi komponen navigasi umum dari bidang dan kapal.

Pada penelitian ini sensor kemiringan $(I M U)$ yang digunakan adalah 6-axis MPU-6050 dari dfrobot, yang terhubung secara I2C. IMU digital ini memiliki 3-axis accelerometer dan 3-axis gyroscope [3].

\section{Perancangan Sistem}

\subsection{Perancangan sistem umum}

Gambar 1 menampilkan diagram blok sistem. Sistem menggunakan input berupa kemiringan sudut dan percepatan sudut serta koordinat. Input kemiringan sudut dan percepatan sudut didapatkan dari Pitch dan Roll sensor IMU. Input dari koordinat hanya sebagai penanda lokasi, GPS akan bekerja ketika sensor membaca adanya indikasi jatuh dan akan mengirimkannya melalui pesan teks. Namun GPS yang digunakan memiliki sutu kelemahan yaitu tidak dapat bekerja didalam ruangan atau di tempat yang sulit terjangkau, Sehingga jika dalam ruangan atau tempat yang sulit dijangkau sistem hanya akan mengirimkan pesan teks yang mengindikasikan bahwa pengguna mengalami musibah jatuh.

Penentuan koordinat lokasi dan pengiriman pesan dilakukan oleh GPS/GPRS/GSM shield menggunakan komunikasi $U A R T$. Dalam sistem kerjanya, GPS dan GSM bekerja secara bergantian dengan sistem switch UART melalui software.

Secara umum sistem ini dapat dituliskan dalam bentuk flowchart seperti pada Gambar 2.

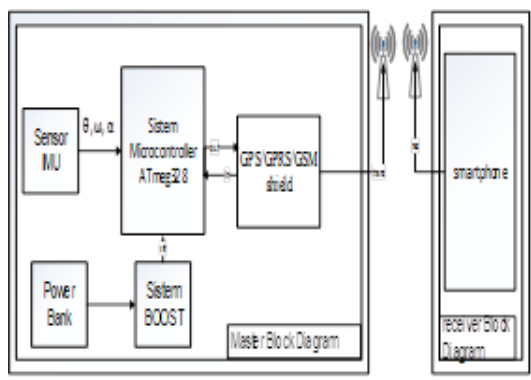

Gambar 1. Diagram Blok sistem

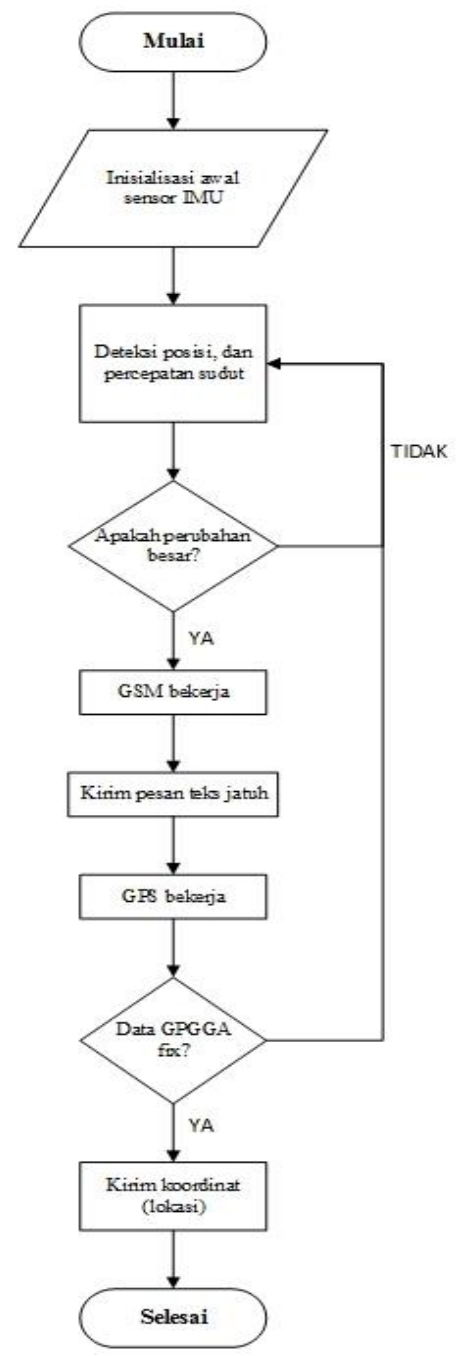

Gambar 2. Flowchart sistem 


\subsection{Perhitungan matematis sensor}

Pada bagian ini dibahas cara mendapatkan kecepatan dan percepatan sudut yang didapat dengan cara menurunkan sudut terhadap waktu, karena pada keluaran sensor IMU yang telah difilter adalah berupa sudut.

Dalam implementasinya, gerak dibagi menjadi dua, yaitu gerak lurus dan gerak rotasi. Gerak lusur memiliki persamaan :

$$
\begin{aligned}
& V=\frac{d S}{d t} \text { untuk kecepatan } \\
& a=\frac{d v}{d t} \text { untuk percepatan }
\end{aligned}
$$

Sedangkan gerak rotasi memiliki persamaan :

$$
\begin{aligned}
& \omega=\frac{d \theta}{d t} \text { untuk kecepatan } \\
& a=\frac{d \omega}{d t} \text { untuk percepatan }
\end{aligned}
$$

Dimana ds dan $d \theta=$ perubahan jarak, sedangkan $d v$ dan $\mathrm{d} \omega=$ perubahan kecepatan.

Persamaan (3) dan (4) digunakan sebagai referensi untuk melakukan perhitungan, karena pada dasarnya output dari sensor yang digunakan adalah sudut. Dari persamaan (3) dan (4) dapat dituliskan seperti pada persamaan (5) sampai (8) dalam implementasi perhitungan pada sistem.

$$
\begin{aligned}
& \omega \Phi x=\frac{d \Phi}{d t}=\frac{(\Phi x-u \Phi x)}{d t} \\
& a \Phi x=\frac{d \Phi}{d t}=\frac{(\omega \Phi x-u \omega \Phi x)}{d t}
\end{aligned}
$$

$\Phi x=u \Phi x$ (berarti sudut saat ini sebagai sudut sebelumnya)

$\omega \Phi x-u \omega \Phi x$ (berarti kecepatan saat ini sebagai kecepatan sebelumnya)

$$
\begin{aligned}
& \omega \theta y=\frac{d \theta}{d t}=\frac{(\theta y-u \theta y)}{d t} \\
& \alpha \theta y=\frac{d \theta}{d t}=\frac{(\omega \theta y-\omega V \theta y)}{d t}
\end{aligned}
$$

$\theta y=u \theta y$ (sudut saat ini sebagai sudut sebelumnya) $\omega \theta y=u \omega \theta$ (kecepatan saat ini sebagai kecepatan sebelumnya)
Dimana untuk kecepatan baik $V \Phi x$ atau $V \theta y$ :

Jika $\omega \Phi x$ atau $\omega \theta y<0$ maka

$\omega \Phi x=-\omega \Phi x$ dan $\omega \theta y=-\omega \theta y$, hal ini dibuat agar nilai kecepatan tidak bernilai negatif.

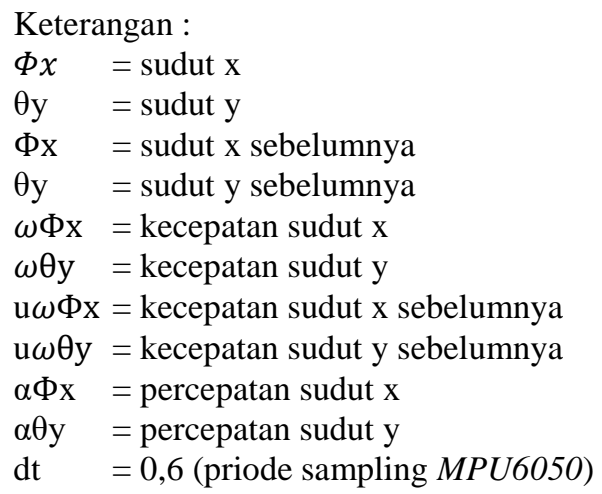

\section{Perancangan Mekanika sistem}

Fall Detection ini terdiri dari sebuah ikat pinggang sebagai pengait, blok penguat dan blok sistem utama yang berupa arduino Uno dan GPS/GPRS/GSM Shield, serta catu daya berupa power bank. Dimensi dari ikat pinggang yang digunakan berukuran $124 \times 3,3 \mathrm{~cm}$. Sedangkan dimensi blok sistem utama berukuran 9,4 X 7,9 X 3 $\mathrm{cm}$, dan dimensi dari blok penguat $(d c$ to $d c$ coverter) berukuuran 7,2 $X 3 \times 3 \mathrm{~cm}$. Ukruan ikat pinggang dapat diatur sesuai dengan lingkar pinggang penggunanya.

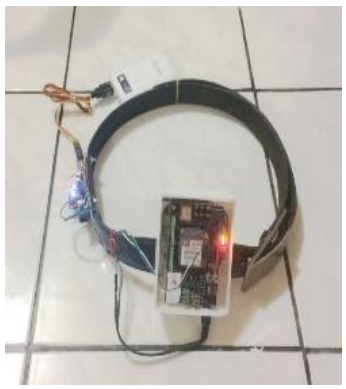

(a)

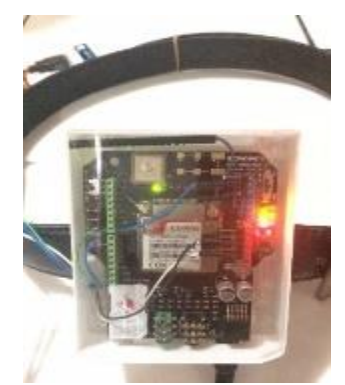

(b)

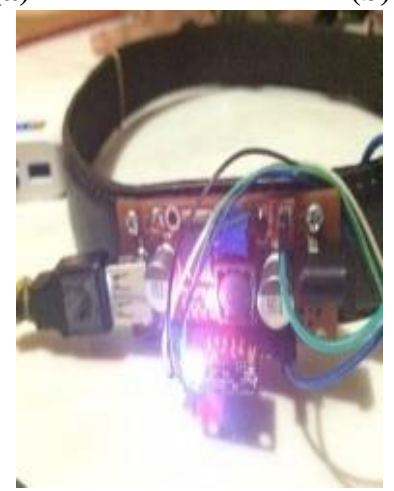

(c)

Gambar 3. (a) bentuk umum fisik fall detection (b) blok sistem utama (c) dc to dc converter 


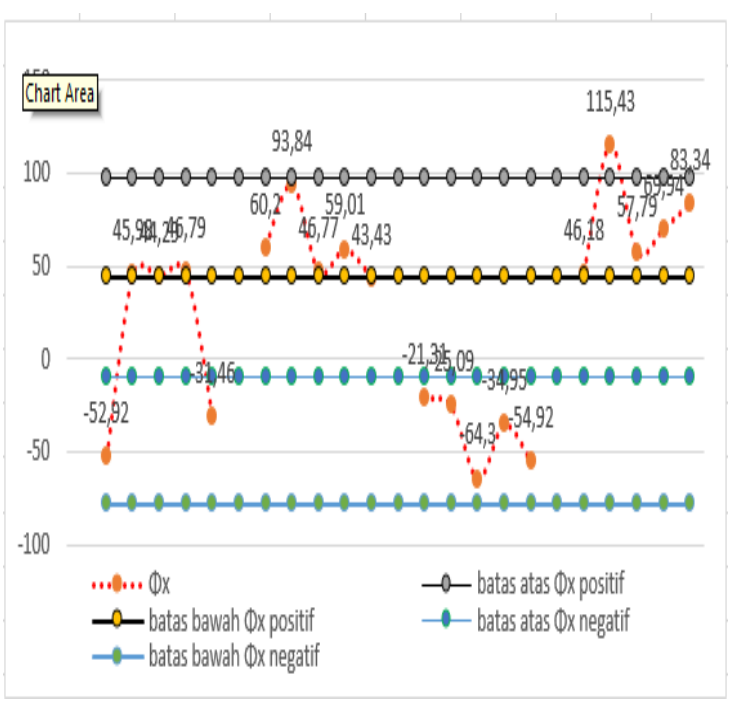

Gambar 4. Grafik sudut terhadap nilai threshold

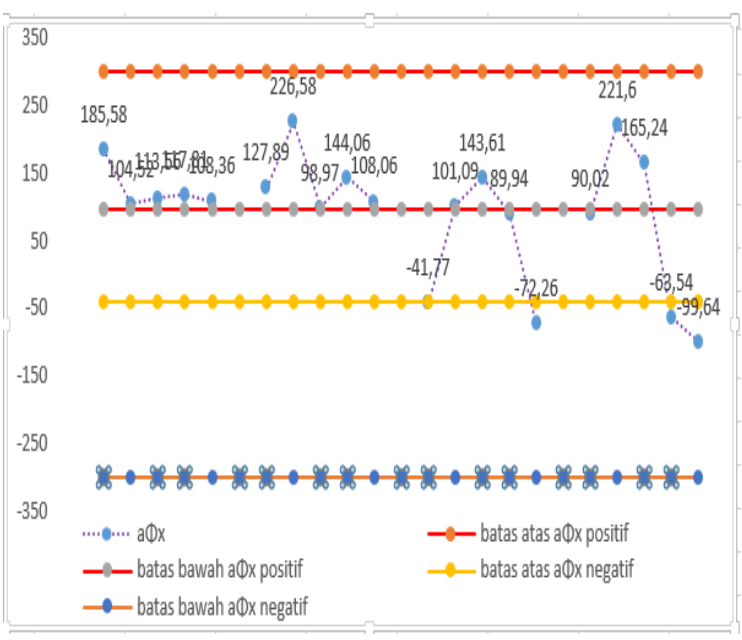

Gambar 5. grafik percepatan sudut terhadap nilai threshold

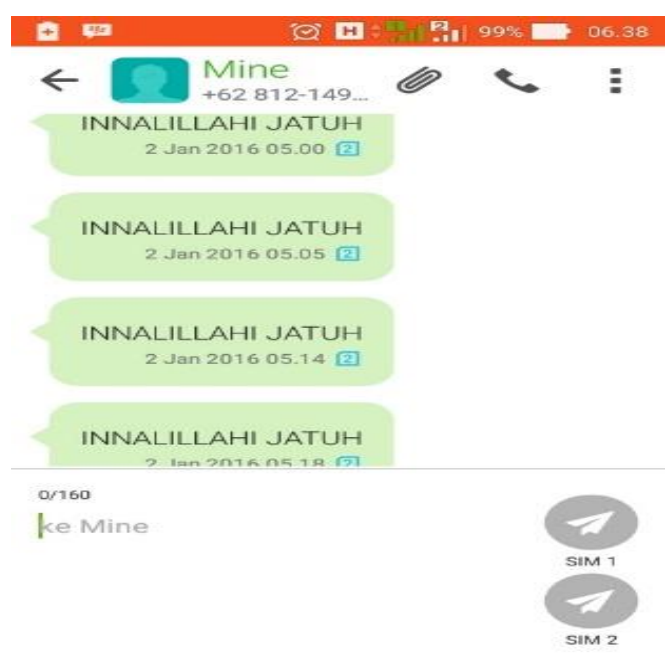

Gambar 6. Tampilan pesan berupa teks "pengguna jatuh

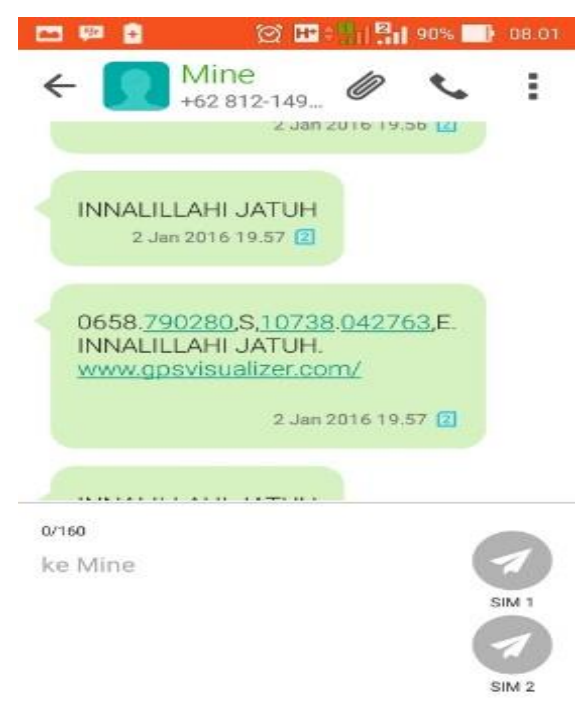

Gambar 7. Gambar pengiriman pesan teks dan koordinat lokasi jatuh.

Tabel 1. Data sudut dan percepatan sudut percobaan jatuh pada sistem

\begin{tabular}{|c|c|c|c|}
\hline No & posisi & $\Phi \mathbf{x}$ & $\mathbf{a \Phi x}$ \\
\hline 1 & \multirow{5}{*}{$\begin{array}{c}\text { jatuh } \\
\text { kedepan }\end{array}$} & $-52,92$ & 185,58 \\
\hline 2 & & 45,98 & 104,52 \\
\hline 3 & & 44,29 & 113,56 \\
\hline 4 & & 46,79 & 117,81 \\
\hline 5 & & $-31,46$ & 108,36 \\
\hline 1 & \multirow{5}{*}{$\begin{array}{c}\text { jatuh } \\
\text { kebelakang }\end{array}$} & 60,2 & 127,89 \\
\hline 2 & & 93,84 & 226,58 \\
\hline 3 & & 46,77 & 98,97 \\
\hline 4 & & 59,01 & 144,06 \\
\hline 5 & & 43,43 & 108,06 \\
\hline 1 & \multirow{5}{*}{$\begin{array}{c}\text { jatuh } \\
\text { kekanan }\end{array}$} & $-21,31$ & $-41,77$ \\
\hline 2 & & $-25,09$ & 101,09 \\
\hline 3 & & $-64,3$ & 143,61 \\
\hline 4 & & $-34,95$ & 89,94 \\
\hline 5 & & $-54,92$ & $-72,26$ \\
\hline 1 & \multirow{5}{*}{ jatuh kekiri } & 1618 & 8007 \\
\hline$\frac{1}{2}$ & & $\begin{array}{c}40,10 \\
115,43\end{array}$ & 221,6 \\
\hline 3 & & 57,79 & 165,24 \\
\hline 4 & & 69,94 & $-63,54$ \\
\hline 5 & & 83,34 & $-99,64$ \\
\hline
\end{tabular}

\section{Pengujian dan Analisis}

Pengujian pada sistem dilakukan untuk melihat respon dari sistem terhadap nilai threshold yang telah dibuat. Pengujian dilakukan dengan melakukan jatuh ke depan, ke belakang, samping kanan, dan samping kiri sebanyak 5 kali percobaan. Besarnya nilai threshold yang diberikan sebesar sudut $x$ positif antara 44 hingga 98 , sudut $x$ negatif 
-10 hingga -78 , peecepatan sudut $\mathrm{x}$ positif antara 98 hingga 300 , percepatan sudut $x$ negatif antara -41 hingga -300 .

Hasil percobaan seperti ditunjukan pada Gambar 4 dan Gambar 5.

Pada Tabel 1 terdapat percobaan yang gagal, yaitu pada saat percobaan jatuh ke belakang pada data ke lima dan juga percobaan jatuh kekiri data pertama. Hal ini terjadi karena pergerakan sensor yang kurang stabil saat percobaan dilakukan. Namun secara keseluruhan keberhasilan data percobaan mencapai nilai $82 \%$.

Pengujian yang selanjutnya adalah pngujian sistem dalam melakukan pengiriman pesan berupa teks dan koordinat lokasi ketika sistem mendeteksi terjadinya jatuh. percobaan dilakukan didalam ruangan dan di luar ruangan. Hasil yang didapatkan berhasil $100 \%$, namun waktu repon terjadi antara rentang waktu antara 3 hingga 10 detik untuk pengiriman pesan berupa teks "pengguna jatuh". serta membutuhkan waktu 7 detik hingga 3 menit dalam pengambilan data GPS lalu mengirimkan melalui pesan singkat. Hasil dari pengiriman pesan seperti pada Gambar 6 dan 7 .

\section{Kesimpulan}

Berdasarkan hasil pengujian dan analisis yang telah dilakukan pada perangkat yang dibangun, dapat diambil kesimpulan sebagai berikut:

1. Sensitifitas pada sistem sangat tinggi sehingga dalam penggunaannya tidak dapat digunakan dalam keadaan lari ataupun kegiatan yang akan menimbulkan sistem mendeteksi percepatan sudut yang tinggi.

2. Dari hasil yang didapatkan pada pengujian, masukan sensor MPU6050 yang mempengaruhi sistem adalah sudut $(\theta) X$ dan Percepatan sudut ( $a \theta) \mathrm{X}$

3. Akurasi dalam percobaan mencapai angka $82 \%$ dari 25 sample percobaan jatuh

4. Sistem berhasil melakukan pengiriman data baik dalam ruangan maupun diluar ruangan walaupun dalam pengiriman untuk lokasi ketika pengujian diluar ruangan sangat lamban, hal ini dikarenakan kemampuan sistem dalam menangkap data GPS yang fix (\$GPGGA).

\section{Daftar Pustaka}

[1] Kadir, A. "Panduan Praktis Mempelajari Aplikasi Mikrokontroler Dan Pemrogramannya Menggunakan Arduino". Yogyakarta: C.V Andi Offset, 2013

[2] Robot, D.F,"GPS/GPRS/GSM Module V3.0 (SKU:TEL0051)". Diakses pada tanggal 21 Desember 2015 http://www.dfrobot.com/wiki/index.php/GPS/ GPRS/GSM_Module_V3.0_(SKU:TEL0051)

[3] DFROBOT,"MPU-6000/6050". Diakses pada tanggal 21 desember 2015 dari http://www.dfrobot.com/index.php?route=prod uct/product\&path=36_56\&product_id=880

[4] Zahir, M. R., “ Implementasi Kalman Filter dan Kontroler PID Untuk Robot Pendulum Terbalik". Bandung, Telkom University, 2015.

[5] Liandana, M., "Deteksi Jatuh Untuk Lanjut Usia Dengan menggunakan Total Akselerasi Dan Sudut Kemiringan Berbasis Smartphone Android”. Yogyakarta: Universitas Gadjah Mada. 2014

[6] Khawandi, S., Daya, B., and Chauvet, P. "Implementation of a monitoring system for fall detection in elderly healthcare," Procedia Computer Science, vol. 3, no. 0, pp. 216-220, 2011

[7] FATE. 2011. Fall Detection For Elderly. Diakses 3 Mei 2015 dari: http://fate.upc.edu/project 